\title{
スライディングモード制御による入力むだ時間システムの安定化*
}

\author{
隅 田悟士*1, 小 口 俊 樹*2
}

\section{Stabilization of Input Delay Systems by Using Sliding Mode Control}

\author{
Satoshi SUMITA and Toshiki OGUCHI*3 \\ ${ }^{* 3}$ Graduate School of Engineering, Tokyo Metropolitan University, \\ 1-1 Minami-osawa, Hachioji-shi, Tokyo, 192-0397 Japan
}

\begin{abstract}
In this paper, we consider the stabilization problem of linear systems with time-delay at the input by using a sliding mode control. Sliding Mode Control (SMC) is a well-known robust control method for systems with model uncertainties and disturbances and a large number of the design methods for finite dimensional systems have been proposed. However there are a few design methods which are applicable for input-delay systems. To overcome the drawback, we analyze the stability of inputdelay systems with switching inputs by transforming the systems into the equivalent systems with time-varying feedback gain. As a result, we show that input-delay systems cannot be asymptotically stabilized by the SMC with signal function. Then we derive a sufficient condition for asymptotic stability of the systems with SMC. Thereafter we propose a SMC design method for systems with uncertain delay at the input. The effectiveness of the proposed methods are illustrated by numerical simulations.
\end{abstract}

Key Words : Nonlinear Control, Robust Control, Computer Control, Input Delay Systems, Sliding Mode Control

\section{緒 \\ スライディングモード制御（SMC）は，モデル不確} かさや外乱に対して優れたロバスト性能をもつ制御手 法として知られている. しかしながら, 実システムに 散見されるむだ時間システムへ直接適用することがで きないため, SMCのむだ時間系システムへの理論的 拡張を試みる研究がなされている.

状態むだ時間システムに対する SMC の設計法とし て, Shyu ら ${ }^{(1)}$ は状態変数の過去の值を含む汎関数から なる切換面を構成する手法, Gouaisbaut $ら^{(2)}$ はむだ時 間の大きさに依存した安定論に基づく LMI を用いた SMC の設計手法を提案しているが，いずれも状態む だ時間システムを対象としており，入力むだ時間を扱 うことはできない, 一方, Roh ら ${ }^{(3)(4)}$ は状態予測器を 用いる手法, 隅田ら ${ }^{(5)}$ はモデル変換を用いる手法によ り，入力むだ時間システムに対する SMC 設計法を提 案している. しかしながら, 入力むだ時間システムの 制御系設計問題を有限次元システムの制御系設計問題 に帰着させた SMC 設計手法であり，本質的に入力む だ時間が存在する場合の SMC の設計理論の検討がな

* 原稿受付 2006 年 3 月 3 日

*1 首都大学東京大学院工学研究科(-192-0397 八王子市南大 沢 1-1).

*2 正員, 首都大学東京大学院工学研究科.

E-mail : oguchi@ctrl.prec.metro-u.ac.jp
されていない. 従って, 入力むだ時間の影響がシステ ムに残る場合, 例えば, むだ時間にモデル化誤差が含 まれ，前述の手法を用いてもむだ時間が完全に相殺さ れない場合には，それらの設計手法を適用できない．

本論文では, 入力むだ時間システムに対して SMC を用いたシステムの安定性について検討する.はじめ に, 切換システムの安定性を解析するために切換制御 則をそれと等価な状態フィードバックとして扱う。そ の形式的に連続化された入力を用いて相対的に短い入 力むだ時間がある場合の安定性を検討する. その結果, 単純な切換制御則から構成される SMC では, 僅かで もむだ時間がある場合には，原点の漸近安定化が図れ ないことを明らかにする. また, 原点が渐近安定とな るために制御則が満たすべき条件の導出を行う. 次に 相対的に長い入力むだ時間が存在する場合の SMC を 検郡し, Arstein ${ }^{(6)}$ のデルリダクション法のモデル変 換を併用した SMC の設計法について述べる.この場 合, むだ時間にモデル化誤差が含まれるならば変換後 のシステムは誤差分のむだ時間を入力にもつシステム に変換される. そこで, このような場合において, 原 点が漸近安定となる条件の導出を行う. 最後に数值例 を用いて提案手法の有効性を示す。 


\section{1. 站}

$1 \cdot 1$ スライディングモード制御はじめに SMC 設計の概要を示すため, 次の可制御正準系を考える.

$$
\begin{aligned}
\dot{x}(t) & =\left[\begin{array}{cccccc}
0 & 1 & 0 & \ldots & \ldots & 0 \\
0 & 0 & 1 & 0 & \ldots & 0 \\
\vdots & & \ddots & & \vdots \\
0 & \ldots & 0 & 1 & 0 \\
0 & \ldots & \ldots & 0 & 1 \\
a_{1} & a_{2} & \ldots & a_{n-1} & a_{n}
\end{array}\right] x(t)+\left[\begin{array}{l}
0 \\
\vdots \\
0 \\
1
\end{array}\right] u(t) \\
& =A x(t)+B u(t)
\end{aligned}
$$

ここで, $x \in \mathbb{R}^{n}$ は状態, $u \in \mathbb{R}$ は操作入力である. $x$ - 空 間上において, 適切な切換面 $\sigma(x(t))=R x(t)=0, R=$ $\left[r_{1} \cdots r_{n}\right] \in \mathbb{R}^{n}$ を定める. 状態が切換面上にあるならば

$$
x_{n}=-\frac{r_{1}}{r_{n}} x_{1}-\frac{r_{2}}{r_{n}} x_{2}-\cdots-\frac{r_{n-1}}{r_{n}} x_{n-1}
$$

が成り立つことから, システム (1) の挙動は次式の 低次元システムで表現される.

$$
\begin{aligned}
\dot{x}(t) & =\left[\begin{array}{cccccc}
0 & 1 & 0 & \ldots & \ldots & 0 \\
0 & 0 & 1 & 0 & \ldots & 0 \\
\vdots & & \ddots & & \vdots \\
0 & \ldots & 0 & 1 & 0 \\
0 & \ldots & \ldots & 0 & 1 \\
-\frac{r_{1}}{r_{n}} & -\frac{r_{2}}{r_{n}} & \ldots & \ldots & \ldots & -\frac{r_{n-1}}{r_{n}}
\end{array}\right] \bar{x}(t) \\
& =A_{s} \bar{x}(t)
\end{aligned}
$$

ただし, $\bar{x} \in \mathbb{R}^{n-1}, \bar{x}_{i}=x_{i}(i=1 \ldots n-1), A_{s} \in$ $\mathbb{R}^{(n-1) \times(n-1)}$ である. ここで $r_{n}=1$ として, 行列 $A_{s}$ が 安定な固有值 $\eta_{1}, \cdots, \eta_{n-1}$ をもつように切換面 $R x=0$ の係数べクトル $\left[r_{1} \cdots r_{n-1} 1\right]$ を定める. このとき, 次 式が成り立つ.

$$
\begin{aligned}
& s^{n-1}+r_{n-1} s^{n-2}+\cdots+s r_{2}+r_{1} \\
& =\left(s-\eta_{n-1}\right)\left(s-\eta_{n-2}\right) \cdots\left(s-\eta_{1}\right)=0
\end{aligned}
$$

次に, 切換面に状態を拘束させるための切換制御則 を導出する. リアプノフ関数として

$$
V(x(t))=\frac{1}{2} \sigma^{2}(x(t))
$$

を選ぶことで, 次の切換条件

$$
\begin{cases}\sigma(x(t))>0 \text { のとき } & \dot{\sigma}(x(t))<0 \\ \sigma(x(t))<0 \text { のとき } & \dot{\sigma}(x(t))>0\end{cases}
$$

に基づき, 次の切換制御則が導かれる.

$$
\begin{aligned}
u(t) & = \begin{cases}-(R B)^{-1}(R A x(t)+\alpha), & \sigma(x(t))>0 \text { のとき } \\
-(R B)^{-1}(R A x(t)-\alpha), & \sigma(x(t))<0 \text { のとき }\end{cases} \\
& =u_{l}+u_{n}
\end{aligned}
$$

ただし， $\alpha>0, u_{l}=-(R B)^{-1} R A x(t), u_{n}=$ $-(R B)^{-1} \alpha \operatorname{sgn}(\sigma(x(t)))$ である. sgn は符号関数 であり, 次のように与えられる.

$$
\operatorname{sgn}(x)= \begin{cases}1 & x>0 \\ 0 & x=0 \\ -1 & x<0\end{cases}
$$

1.2 入力の形式的な連経化次節で入力むだ時 間システムに切換制御則（7）を適用したときの安定条 件を導出するために，その準備として切換制御則（7） を次式で書き換える。

$$
\begin{aligned}
u(t) & =-(R B)^{-1}\left(R A x(t)+\frac{R x(t)}{|R x(t)|} \alpha\right) \\
& =-(R B)^{-1} R(A+k I) x(t)
\end{aligned}
$$

ただし，

$$
k=\frac{\alpha}{|\sigma(x(t))|}
$$

である. 置き換えられた制御則 (9) は切換関数 $\sigma(x(t))$, つまり切換面との距離に依存する变動ゲインをもつ状 態フィードバックとみなすことができる. 入力むだ時 間システムにおいては，それが原因となり，漸近安定 化できないことを次節で述べる.

\section{2. 入力むだ時間システムの安定化}

2.1 むだ時間が短い场合＼cjkstart本節では，システム に対して相対的に短い入力むだ時間が存在する場合を 考える.

$$
\begin{aligned}
& \dot{x}(t)=(A+\Delta A) x(t)+(B+\Delta B) u(t-\Delta h) \\
& x(0)=x_{0}, \quad u(t)=\phi(t) \quad t \in[-\Delta h, 0]
\end{aligned}
$$

ここで, $x \in \mathbb{R}^{n}$ は状態, $\Delta h \in \mathbb{R}$ は $0 \leq \Delta h \leq \bar{h}$ を満た すむだ時間， $u \in \mathbb{R}$ は操作入力, $A \in \mathbb{R}^{n \times n}, B \in \mathbb{R}^{n}$ で 表される $(A, B)$ は可制御正準対, $x_{0} \in \mathbb{R}^{n}$ はシステム の初期条件, $\phi(t): \mathbb{R} \rightarrow \mathbb{R}$ は入力の初期条件を表す連 続関数ベクトルである. また, $\Delta A \in \mathbb{R}^{n \times n}, \Delta B \in \mathbb{R}^{n}$ は不確かさを表し

$$
\Delta A=D_{0} \Delta_{0} E_{0}, \Delta B=D_{1} \Delta_{1} E_{1}
$$

とする.ここで, $D_{0} \in \mathbb{R}^{n \times n}, E_{0} \in \mathbb{R}^{n \times n}, D_{1} \in \mathbb{R}^{n \times n}$, $E_{1} \in \mathbb{R}^{n}$ は各々既知の定数行列, $\Delta_{0} \in \mathbb{R}^{n \times n}, \Delta_{1} \in \mathbb{R}^{n \times n}$ は

$$
\Delta_{0}^{T} \Delta_{0} \leq I, \Delta_{1}^{T} \Delta_{1} \leq I
$$

を満たす未知の行列である. 
切換制御則（7）を適用したときの安定条件を導出 するために入力（9）をシステム（11）に代入すると

$$
\begin{aligned}
\dot{x}(t)= & (A+\Delta A) x(t) \\
& -(B+\Delta B)(R B)^{-1} R(A+k I) x(t-\Delta h) \\
= & (A+\Delta A) x(t)+\left(A_{d}+\Delta A_{d}\right) x(t-\Delta h)
\end{aligned}
$$

ただし, $A_{d}=-B(R B)^{-1} R(A+k I), \Delta A_{d}=$ $-\Delta B(R B)^{-1} R(A+k I)$ である.このとき, 次の定 理が成り立つ.

定理 1 任意の入力むだ時間 $h>0$ に対して, $\Delta_{0}=$ $\Delta_{1}=0$ としたときのシステム（14）が $k>\bar{k}$ のときに 複素右半平面に極をもつような $\bar{k} か ゙$ 必ず存在する.

（証明） $\Delta_{0}=\Delta_{1}=0$ の下でシステム（14）の極を $s$ とすると特性方程式は

$$
\operatorname{det}\left|s I-A-e^{-s h} A_{d}\right|=0
$$

である. $r_{n}=1$ とすると

$$
\begin{aligned}
A_{d} & =-B(R B)^{-1} R(A+k I) \\
& =\left[\begin{array}{ccc}
0 & \ldots \ldots \ldots \cdots \cdots & 0 \\
\vdots & & \vdots \\
0 & \ldots \ldots \ldots \cdots \cdots & 0 \\
a_{1}+k r_{1} & a_{2}+k r_{2}+r_{1} \cdots a_{n}+k+r_{n-1}
\end{array}\right]
\end{aligned}
$$

これより, $\theta_{i}=a_{i}-e^{-s h}\left(a_{i}+k r_{i}+r_{i-1}\right), \quad r_{0}=0$ とす ると

$$
A+e^{-s h} A_{d}=\left[\begin{array}{cccccc}
0 & 1 & 0 & \ldots & \ldots & 0 \\
0 & 0 & 1 & 0 & \ldots & 0 \\
\vdots & & \ddots & & \vdots \\
0 & \ldots & 0 & 1 & 0 \\
0 & \ldots & \ldots & 0 & 1 \\
\theta_{1} & \theta_{2} & \ldots & \theta_{n-1} & \theta_{n}
\end{array}\right]
$$

であるから，特性方程式は

$$
\begin{aligned}
& s^{n}+\left\{-a_{n}+e^{-s h}\left(a_{n}+k+r_{n-1}\right)\right\} s^{n-1} \\
& +\left\{-a_{n-1}+e^{-s h}\left(a_{n-1}+k r_{n-1}+r_{n-2}\right)\right\} s^{n-2} \\
& +\cdots+\left\{-a_{2}+e^{-s h}\left(a_{2}+k r_{2}+r_{1}\right)\right\} s \\
& +\left\{-a_{1}+e^{-s h}\left(a_{1}+k r_{1}\right)\right\} \\
= & s^{n}-a_{n} s^{n-1}-\cdots-a_{1} \\
& -e^{-s h} s^{n}+e^{-s h}\left(a_{n} s^{n-1}+\cdots+a_{1}\right) \\
& +e^{-s h} s^{n}+e^{-s h}\left\{\left(k+r_{n-1}\right) s^{n-1}+\cdots+k r_{1}\right\} \\
= & \left(1-e^{-s h}\right)\left(s^{n}-a_{n} s^{n-1}-\cdots-a_{1}\right) \\
& +e^{-s h}\left(s^{n}+\left(k+r_{n-1}\right) s^{n-1}+\cdots+k r_{1}\right) \\
= & \left(1-e^{-s h}\right) \Pi_{i=1}^{n}\left(s-\alpha_{i}\right)+e^{-s h} \Pi_{i=1}^{n-1}\left(s-\eta_{i}\right)(s+k) \\
= & 0
\end{aligned}
$$

ただし， $\alpha_{i}$ は $A$ の固有値， $\eta_{i}$ は式（4）で定義され た行列 $A_{s}$ の固有值である. ここで, 特性方程式の根 $s=\mu+j v(\mu, v \in \mathbb{R})$ を複素平面上のベクトル $(u, v)$ とすると特性方程式（18）は次式と等価である.

$$
e^{\mu h} a=e^{-j v h}(a-b)
$$

ただし, $a=\Pi_{i=1}^{n}\left(\mu+j v-\alpha_{i}\right), \quad b=\Pi_{i=1}^{n-1}(\mu+j v-$ $\left.\eta_{i}\right)(s+k)$ である. $|\boldsymbol{b}|=\Pi_{i=1}^{n-1}\left|\mu+j v-\eta_{i}\right||\mu+j v+k|$ より, $k \rightarrow \infty$ のとき, $|\boldsymbol{b}| \rightarrow \infty$ であるから, 固定され た $\mu, v$ に対して任意の $k>\bar{k}$ に対して

$$
e^{\mu h}|a|<|a-b|
$$

を满たす十分に大きい $\bar{k}$ が存在する. 次に $v \rightarrow \infty$ と すると

$$
\begin{aligned}
& \arg (\boldsymbol{a})=\sum_{i=1}^{n} \arg \left(\mu+\operatorname{Re}\left[\alpha_{i}\right]+j\left(v+\operatorname{Im}\left[\alpha_{i}\right]\right)\right) \rightarrow \frac{\pi}{2} n \\
& \arg (\boldsymbol{b})=\sum_{i=1}^{n-1} \arg \left(\mu+\operatorname{Re}\left[\eta_{i}\right]+j\left(v+\operatorname{Im}\left[\eta_{i}\right]\right)\right) \\
& +\arg (\mu+k+j v) \rightarrow \frac{\pi}{2} n \\
& \frac{|\boldsymbol{a}|^{2}}{|\boldsymbol{b}|^{2}}=\frac{\left(\mu+\operatorname{Re}\left[\alpha_{n}\right]\right)^{2}+\left(v+\operatorname{Im}\left[\alpha_{n}\right]\right)^{2}}{(\mu+k)^{2}+v^{2}} \\
& \times \Pi_{i=1}^{n-1} \frac{\left(\mu+\operatorname{Re}\left[\alpha_{i}\right]\right)^{2}+\left(v+\operatorname{Im}\left[\alpha_{i}\right]\right)^{2}}{\left(\mu+\operatorname{Re}\left[\eta_{i}\right]\right)^{2}+\left(v+\operatorname{Im}\left[\eta_{i}\right]\right)^{2}} \\
& \rightarrow 1
\end{aligned}
$$

となる.これより, $v \rightarrow \infty$ のき, $|\boldsymbol{a}-\boldsymbol{b}| \rightarrow 0$ となる. $v \rightarrow \infty$ のとき, 式 (20) の右辺は 0 に収束し, 一方, 左辺は $心$ に発散するので

$$
e^{\mu h}|a|=|a-b|
$$

を満たす $v_{0}$ が必ず存在する. 式（22）は式（19）の 両辺のベクトルの長さが等しいことを表している.こ のとき, べクトル $\boldsymbol{a},(\boldsymbol{a}-\boldsymbol{b})$ のなす角度が $\theta$ であるな らば, 入力むだ時間 $h$ が

$$
h=h_{n}=\frac{\theta+2 \pi q}{v_{0}}(q \in \mathbb{Z})
$$

のとき, 式（19）が成り立つ. 以上の議論は $\mu$ の符 号を問わないから, システム (11) が右半平面に極を もつ場合にも成り立つ.さて， $k$ を大きくすれば, 式 （20）の右辺を大きくすることができる．よって，式 （22）を満たす $v_{0}$ を任意に大きくすることができ，そ の結果, 式 (23) より $h_{0}=\theta / v_{0}$ を任意に小さくする ことができる. すなわち，任意の入力むだ時間に対し て, 複素右半平面に極をもつような $\bar{k} か ゙$ 必ず存在する. 
$\alpha$ を定数とした切換制御則（7）では，切換面近傍 において切換制御則（7）と等価な入力（9）の $k=$ $\alpha / \mid \sigma(x(t))) \mid$ が無限大となる. ゆえに僅かでも入力む だ時間が存在するならば, 入力むだ時間システム (11) を切換制御則（7）によって漸近安定化できないこと を定理 1 は示している.

さて, システム（11）の漸近安定化について, 次の ことがいえる.

定理 2 システム (14) が $k_{\min } \leq k \leq k_{\max }$ において, 漸近安定であるならば,

$$
k_{\min }|\sigma(x(t))| \leq \alpha \leq k_{\max }|\sigma(x(t))|
$$

を区間 $\left[0, \sigma_{\max }\right]$ で満たす連続な関数 $\alpha(|\sigma(x(t))|)$ を用 いた制御則（7）によりシステム（11）の状態 $x \in V$

$$
V=\left\{x|| \sigma(x(t)) \mid \leq \sigma_{\max }\right\}
$$

は原点へ漸近的に収束する.

（証明） 状態 $x$ が $V$ に属するならば，条件（24） より $k_{\min } \leq k \leq k_{\max }$ が成り立つことから明らかである.

定理 2 において，条件（24）をある有限な空間で満 たす関数 $\alpha$ の候補として, 例えば, 次の関数が挙げら れる.

$$
\alpha(|\sigma|)= \begin{cases}k_{\max }|\sigma| & |\sigma|<\phi \text { のとき } \\ \alpha_{\max }=k_{\max } \phi & |\sigma| \geqq \phi \text { のき }\end{cases}
$$

ただし， $\alpha>0, k_{\max }>0, \phi>0$ は定数とする. 関 数（26）はチャタリングを防ぐ方法の 1 つとして知ら れている飽和関数である. $\alpha$ として関数（26）を用い た場合，これは条件 (24) を区間 $\left[0, \alpha_{\max } / k_{\min }\right]$ で满た す. 条件（24）は $\sigma=0$ のときに $\alpha=0$ を意味し，こ れは式（7）における $u_{n}$ を連続化することを意味する.

システム（14）が $k_{\min } \leq k \leq k_{\max }$ において，濑近安 定である条件は，むだ時間システムの安定論 ${ }^{(9)}$ に基づ いて, 次のように与えられる.

系 $10<k_{\min } \leq k \leq k_{\max }$ の範囲で次の LMI

$$
\begin{aligned}
& {\left[\begin{array}{cccc}
M_{11} & H_{1} & H_{2} & H_{3} \\
H_{1}^{T} & -J_{1} & 0 & 0 \\
H_{2}^{T} & 0 & -J_{2} & 0 \\
L_{3}^{T} & 0 & 0 & -J_{3}
\end{array}\right]<0} \\
& M_{11} \equiv\left(A+A_{d}(k)\right) X+X\left(A+A_{d}(k)\right)^{T}+\eta_{0} D_{0} D_{0}^{T} \\
& +\left(\eta_{1}+\varepsilon_{1} \bar{h}\right) \bar{D}_{1}(k) \bar{D}_{1}^{T}(k)+\bar{h} A_{d}\left(P_{11}+P_{11}\right) A_{d}^{T}
\end{aligned}
$$

$$
\begin{aligned}
& H_{1} \equiv\left[X E_{0}^{T} X \bar{E}_{1}(k)^{T}\right] \\
& H_{2} \equiv\left[\bar{h} A_{d}\left(P_{10}+P_{11}\right) \bar{E}_{1}^{T}(k)\right] \\
& H_{3} \equiv\left[\bar{h} X A_{0}^{T} \bar{h} X E_{0}^{T} \bar{h} X A_{1}^{T} \bar{h} X \bar{E}_{1}^{T}(k)\right] \\
& J_{1} \equiv \operatorname{diag}\left[\begin{array}{ll}
-\eta_{0} I & \eta_{1} I
\end{array}\right] \\
& J_{2} \equiv \bar{h}\left(-\varepsilon_{1} I+\bar{E}_{1}(k)\left(P_{10}+P_{11}\right) \bar{E}_{1}^{T}(k)\right) \\
& J_{3} \equiv \operatorname{diag}\left[\begin{array}{llll}
J_{31} & J_{32} & J_{33} & J_{34}
\end{array}\right] \\
& J_{31} \equiv-\bar{h} P_{10}+\rho_{10} \bar{h} D_{0} D_{0}^{T}, J_{32} \equiv-\Delta I \rho_{10} \\
& J_{33} \equiv-\bar{h} P_{10}+\rho_{10} \bar{h} D_{0} D_{0}^{T}, J_{34} \equiv-\Delta I \rho_{10}
\end{aligned}
$$

を満たす正定対称行列 $X(k), P_{10}(k), P_{11}(k)$ および正 の定数 $\eta_{0}, \eta_{1}, \varepsilon_{1}, \rho_{10}, \rho_{11}$ が存在するならば, システム (14) は $k_{\text {min }} \leq k \leq k_{\text {max }}$ において，漸近安定である. た だし, $\bar{E}_{1}(k)=E_{1}(R B)^{-1} R(A+k I)$ である.

(証明) 次式のようにリアプノフ関数を選ぶこと により, 安定条件が導かれる(9).

$$
\begin{aligned}
& V(x)=x^{T} P x+\int_{-\bar{h}}^{0}\left(\int_{t+\theta}^{t} g_{1}(s)+\int_{t+\theta-\bar{h}}^{t} g_{2}(s) d s\right) d \theta \\
& g_{1}(s)=x^{T}(s)\left(A\left(P_{10}-\rho_{10} D_{0} D_{0}^{T}\right)^{-1} A+\frac{E_{0}^{T} E_{0}}{\rho_{10}}\right) x(s) \\
& g_{2}(s)=x^{T}(s)\left(A\left(P_{11}-\rho_{11} D_{1} D_{1}^{T}\right)^{-1} A+\frac{E_{1}^{T} E_{1}}{\rho_{11}}\right) x(s)
\end{aligned}
$$

まとめると系 1 によりシステム（14）の安定性が保 証され，それと定理 2 から入力（7）をシステム (11) に適用した場合の安定性が保証される.

2.2 むだ時間が長い埸合本小節では, 比較的 長い入力むだ時間を含む線形システムに対してモデル 変換を含めたスライディングモード制御問題を考える. 次の入力むだ時間システムを考える.

$$
\begin{aligned}
& \dot{x}(t)=A x(t)+B u(t-h-\Delta h) \\
& x(t)=\phi(t) \quad t \in[-h, 0]
\end{aligned}
$$

ここで, $h \in \mathbb{R}$ はむだ時間であり，それ以外の記号は 式（11）と同様である. また, $\Delta h \in \mathbb{R}^{n}$ はむだ時間の 不確かさを表し

$$
|\Delta h| \leq \bar{h} \leq h
$$

とする. ここで, 変数変換

$$
z(t)=x(t)+\int_{t-h}^{t} e^{A(t-h-\theta)} B u(\theta) d \theta
$$

を導入すると, システム（29）は次式に変換される.

$$
\begin{aligned}
\dot{z}(t)= & A z(t)+e^{-A h} B u(t) \\
& +B u(t-h-\Delta h)-B u(t-h)
\end{aligned}
$$


システム（32）に正則変換 $T w=z$ を行い, むだ時間 のない部分を可制御正準系に変換すると

$$
\begin{aligned}
\dot{w}(t)= & A w(t)+B u(t) \\
& +T^{-1} B\{u(t-h-\Delta h)-u(t-h)\}
\end{aligned}
$$

$\Delta h=0$ ならば，次式に示すようにむだ時間が陽に現 れないシステムが得られる.

$$
\dot{w}(t)=A w(t)+B u(t)
$$

これに 1 節で示した方法により適切な切換面 $\sigma=R w=$ 0 を設計する、設計された SMC と等価な入力は, 式 （7）の $x$ を $w$ に置き換えたものであり，それをシステ 厶（33）に代入すると

$$
\dot{w}(t)=A_{f b} w(t)+A_{f b d}\{w(t-h)-w(t-h-\Delta h)\}
$$

ただし, $A_{f b}=A-B(R B)^{-1} R(A+k I), A_{f b d}=$ $T^{-1} B\left(R B_{t}\right)^{-1} R(A+k I)$ である.

システム（35）が $k_{\text {min }} \leq k \leq k_{\text {max }}$ において, 漸近安 定である条件は，むだ時間システムの安定論 ${ }^{(9)} に$ 基づ いて, 2.1 節と同様に次の系が与えられる.

系 2 次の $\mathrm{LMI}$ を $0<k_{\text {min }} \leq k \leq k_{\max }$ の範囲で満 たす正定対称行列 $X(k), P_{10}(k), P_{11}(k)$ および正の定数 $\eta_{0}, \eta_{1}, \varepsilon_{1}, \rho_{10}, \rho_{11}$

$$
\begin{aligned}
& {\left[\begin{array}{cc}
A_{f b} P+P A_{f b}+(2 h+\bar{h})\left(Q_{0}+Q_{1}+Q_{2}\right) & M^{T} \\
M & \bar{Q}
\end{array}\right]<0} \\
& M^{T} \equiv\left[\begin{array}{ll}
M_{1}^{T} & \left.M_{2}^{T}\right]
\end{array}\right. \\
& M_{1}^{T} \equiv h\left[\begin{array}{ll}
P A_{f b} A_{f b d} P A_{f b d}^{2} & \left.-P A_{f b d}^{2}\right]
\end{array}\right. \\
& M_{2}^{T} \equiv-(h+\bar{h})\left[\begin{array}{ll}
P A_{f b} A_{f b d} & -P A_{f b d}^{2} P A_{f b d}^{2}
\end{array}\right] \\
& Q \equiv \operatorname{diag}\left[\begin{array}{ll}
Q_{1} & Q_{2}
\end{array}\right] \\
& Q_{1} \equiv h \operatorname{diag}\left[\begin{array}{lll}
Q_{0} & Q_{1} & Q_{2}
\end{array}\right] \\
& Q_{2} \equiv h(h+\bar{h}) \operatorname{diag}\left[\begin{array}{lll}
Q_{0} & Q_{1} & Q_{2}
\end{array}\right]
\end{aligned}
$$

が存在するならば，システム（14） は $k_{\min } \leq k \leq k_{\max }$ において，漸近安定である。

2.3 制御器の設計方法 システムに対して, 入 力むだ時間が相対的に短い場合は以下のように制御器 を設計する。

step1 式（4）より，切換面を設計する.

step2 $k$ を微小な值から適当な值まで変化させながら, $k$ に対する系 1 に示した LMI（27）の可解性を 繰り返し調べる．その結果，LMI（27）が可解 となる範囲 $k_{\text {min }} \leq k \leq k_{\text {max }}$ を求める. step3 式（24）を満たすような関数 $\alpha(x)$ を設計する. また，入力むだ時間が長い場合は以下の手順となる.

step1 変数変換（31）および正則変換より, システム （33）を得る.

step2 むだ時間の不確かさ $\Delta h$ が無い公称モデル

に対して切換面を設計する.

step3 系 2 に示した LMI（36）が可解となる範囲 $k_{\text {min }} \leq$ $k \leq k_{\max }$ を求める.

step4 式（24）の変数 $x$ を変数 $w$ に置き換えた次式を 満たす関数 $\alpha(w)$ を設計する.

$$
k_{\min }|\sigma(w(t))| \leq \alpha \leq k_{\max }|\sigma(w(t))|
$$

\section{3. 数 值 例}

次の入力むだ時間線形システムを考える.

$$
\begin{aligned}
& \dot{x}(t)=(A+\Delta A) x(t)+(B+\Delta B) u(t-0.1) \\
& A=\left[\begin{array}{ccc}
0 & 1 & 0 \\
0 & 0 & 1 \\
0.6-0.7 & -0.8
\end{array}\right] B=\left[\begin{array}{l}
0 \\
0 \\
1
\end{array}\right] \\
& x(t)=\phi(t) \quad t \in[-0.1,0] \\
& \Delta A=D_{0} \Delta_{0} E_{0}, \Delta B=D_{1} \Delta_{1} E_{1} \\
& \Delta_{0}^{T} \Delta_{0} \leq I, \Delta_{1}^{T} \Delta_{1} \leq I \\
& D_{0}=0.2 I, D_{1}=0.1 I \\
& E_{0}=-0.1 I, E_{1}=\left[\begin{array}{lll}
-0.1 & 0.1-0.1
\end{array}\right]^{T}
\end{aligned}
$$

$A$ の固有值は $0.47,-0.63 \pm 0.94 j$ であり，不安定な 固有值をもつ行列である.これを式（26）の $\alpha$ を用 いた制御則（7）により漸近安定化を図る. 切換面上 でのシステム（3）の固有值 $\eta_{1}, \eta_{2}$ および定理 2 にお ける $k_{\text {min }}, k_{\text {max }}$ を，それぞれ， $\eta_{1}=-0.8, \eta_{2}=-1.0$, $k_{\text {max }}=5, k_{\text {min }}=0.5$ とする. 系 1 に従い, $k$ に対して許 容できる入力むだ時間の最大值 $\bar{h}(k)$ を計算した結果を 図 1 に示す. 図 1 より $0 \leq h \leq 0.1$ なるむだ時間に対し て漸近安定化できることが分かる. 式（26）の $\alpha_{\text {max }}$ を $\alpha_{\text {max }}=10$ とすれば, 式 (25) はV $=\{x|| \sigma(x(t)) \mid \leq 20\}$ となる。

式（7）の $\boldsymbol{\alpha}$ を定数とした従来の切換制御則，本提 案手法を用いたシミュレーション結果をそれぞれ図 2, 図 3 に示す.ただし, システムの初期条件および不確 かさを

$$
x(t)=\left[\begin{array}{l}
5 \\
5 \\
5
\end{array}\right] \quad t \in[-h, 0], \Delta_{0}=\Delta_{1}=\left[\begin{array}{ccc}
1 & 0 & 0 \\
0 & -1 & 0 \\
0 & 0 & 1
\end{array}\right]
$$

とした．図 2 より，従来の手法では入力むだ時間シス テムの漸近安定化がなされていないことが分かり，そ 


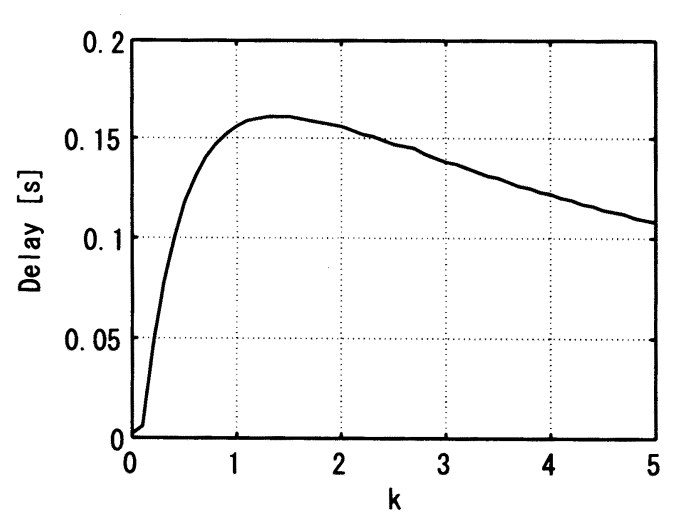

Fig. 1 The maximum allowable delay time

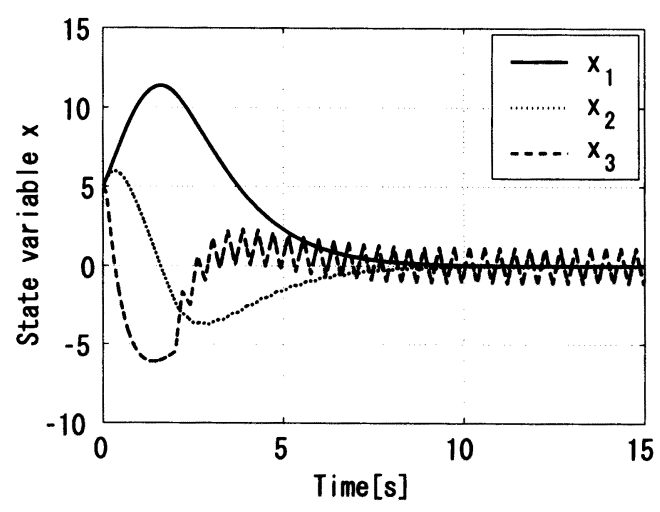

Fig. 2 SMC

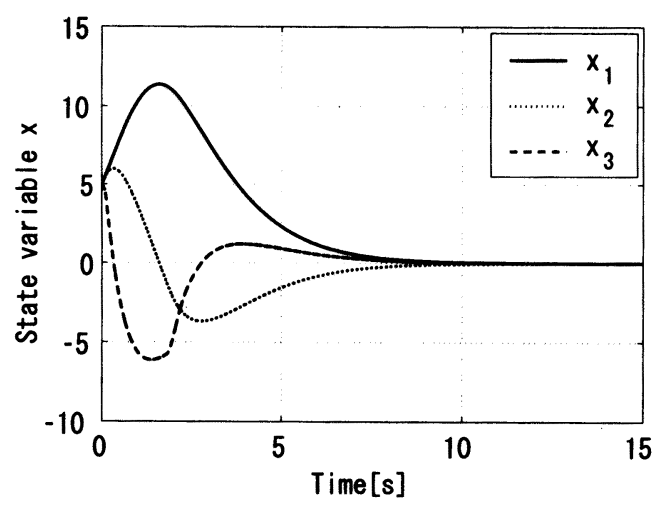

Fig. 3 SMC with continuous function

の根拠は定理 1 による. 一方, 図 3 より, 提案手法で は渐近安定化が達成されていることが分かる.

\section{結}

本論文では, 入力むだ時間システムに対するスライ ディングモード制御系の安定性について検討を行った. はじめに入力むだ時間システムに SMC を適用した場 合の安定性を検討するために切換制御入力を状態依存 の変動ゲインをもつ状態フィードバックに帰着させる ことで，単純な切換制御を用いた SMC では，入力む だ時間システムを漸近安定化できないことを示した. さらにシステムを漸近安定化させる条件を検討し, 得 られた条件を満足するような連続な関数を用いること により, 入力むだ時間システムの漸近安定化が可能と なることを示した. また，入力むだ時間が厳密に既知 である場合のみに安定性が保証されていたモデル変換 による手法を拡張し，入力むだ時間にモデル化誤差を 含まれる場合の安定条件を導出した. 最後に, 導出し た条件に基づくSMC の設計手法を示した.

\section{文献}

(1) K. K. Shyu and J. J. Yan, Robust stability of uncertain time-delay systems and its stablilization by variable structure control, International Journal of Control, Vol.57, No.1, (1993), pp.237-246

(2) F. Gouaisbaut and M. Dambrine and J. P. Richard, Robust control of delay systems: a sliding mode control design via LMI, Systems \& Control Letters, Vol.46, No.4, (2002), pp.219-230

(3) Y. H. Roh and J. H. Oh, Robust stabilization of uncertain input-delay systems by sliding mode control with delay compensation, Automatica, Vol.35, (1999), pp.1861-1865

(4) Y. H. Roh and J. H. Oh, Sliding Mode Control for Robust Stabilization of Uncertain Input-Delay Systems, The Institute of Control, Automation and systems Engineers, KOREA, Vol.2, No.2, (2000), pp.98-103

(5) S. Sumita and T. Oguchi, Sliding Mode Control of Systems with Uncertain Input Delay, Proceedings of the Kanto Branch Regular Meeting of the Japan Society of Mechanical Engineers, (2005), pp.245-246

(6) Z. Artstein, Linear Systems with Delayed Controls, A Reduction, IEEE Transactions on Automatic Control, Vol.27, No.4, (1982), pp.869-879

(7) C. M. Kwan Sliding Mode Control of Lineqr Systems with Mismatched Uncertains, Automatica, Vol.31, No.2, (1995), pp.303-307

(8) K. Gopalsamy, Stability and Oscillations in Dealy Diferential Equations of Population Dynamics, Kluwer Academic Publishers, (1992), pp.219-239

(9) E. K. Boukas and Z. K. Liu, Deterministic and Stochastic Time Delay Systems, Birkhauser, (2002), pp.39-43, 79-84 